Research, Society and Development, v. 9, n. 8, e967997751, 2020

(CC BY 4.0) | ISSN 2525-3409 | DOI: http://dx.doi.org/10.33448/rsd-v9i9.7751

\title{
Práticas Educomunicativas voltadas para a educação em Direitos Humanos
}

Educommunicative Practices for Human Rights Education

Prácticas educomunicativas para la educación en derechos humanos

Recebido: 20/08/2020 | Revisado: 29/08/2020 | Aceito: 14/09/2020 | Publicado: 14/09/2020

Tatiane de Fátima da Silva Pessôa

ORCID: https://orcid.org/0000-0002-3347-8620

Universidade Franciscana, Brasil

E-mail: tatianefpessoa@gmail.com

Taís Steffenello Ghisleni

ORCID: https://orcid.org/0000-0002-5405-9492

Universidade Franciscana, Brasil

E-mail: taisghisleni@yahoo.com.br

Marcos Alexandre Alves

ORCID: https://orcid.org/0000-0002-5271-0624

Universidade Franciscana, Brasil

E-mail: marcosalves@unifra.br

\section{Resumo}

O artigo contextualiza o debate contemporâneo acerca dos Direitos Humanos, fazendo um resgate histórico de como esse tema é tratado em diferentes Constituições e identifica as suas implicações socioculturais na Sociedade de Comunicação e Informação - TICs. A proposta consiste em verificar se a inserção das práticas educomunicativas, como um recurso pedagógico, proporcionam uma formação voltada para a promoção e a preservação dos Direitos Humanos, tão necessários ao desenvolvimento da cidadania e da justiça social. As TICs evoluíram de forma exponencial, o que proporciona aos indivíduos estarem conectados por meio das redes de internet, proporcionando maior visibilidade do comportamento humano. Entretanto, ocasionam, por vezes, graves violações dos direitos fundamentais, haja vista a desterritorialização e a velocidade da informação veiculadas pelas redes sociais. Para isso, empregou-se os métodos de abordagem dedutivo e de procedimento monográfico. Como técnicas de investigação utilizou-se a pesquisa bibliográfica e documental. Por fim, destaca-se que as práticas educomunicativas se constituem como indispensáveis para se pensar e desenvolver uma educação para e em Direitos Humanos, tanto em ambientes formais quanto não formais de ensino. 
Palavras-chave: Sociedade em rede; Educomunicação; Direito à educação; Ética.

\begin{abstract}
The article contextualizes the contemporary debate about Human Rights, making a historical recovery of how this theme is treated in different Constitutions and identifies its socio-cultural implications in the Communication and Information Society - ICTs. The proposal consists in verifying whether the insertion of educommunicative practices, as a pedagogical resource, provides training aimed at the promotion and preservation of Human Rights, so necessary for the development of citizenship and social justice. ICTs have evolved exponentially, which allows individuals to be connected through internet networks, providing greater visibility of human behavior. However, they sometimes cause serious violations of fundamental rights, given the deterritorialization and speed of information conveyed by social networks. For this, the deductive approach and monographic procedure methods were used. As research techniques, bibliographic and documentary research was used. Finally, it is highlighted that the educommunicative practices are essential to think and develop an education for and in Human Rights, both in formal and non-formal teaching environments.
\end{abstract}

Keywords: Network society; Educommunication; Right to education; Ethic.

\title{
Resumen
}

El artículo contextualiza el debate contemporáneo sobre los Derechos Humanos, haciendo una recuperación histórica de cómo se trata este tema en las distintas Constituciones e identifica sus implicaciones socioculturales en la Sociedad de la Comunicación y la Información - TIC. La propuesta consiste en verificar si la inserción de prácticas educomunicativas, como recurso pedagógico, brinda una formación orientada a la promoción y preservación de los Derechos Humanos, tan necesarios para el desarrollo de la ciudadanía y la justicia social. Las TIC han evolucionado de manera exponencial, lo que permite que las personas estén conectadas a través de redes de Internet, proporcionando una mayor visibilidad del comportamiento humano. Sin embargo, en ocasiones provocan graves violaciones a los derechos fundamentales, dada la desterritorialización y rapidez de la información que transmiten las redes sociales. Para ello se utilizó el método deductivo y el procedimiento monográfico. Como técnicas de investigación se utilizó la investigación bibliográfica y documental. Finalmente, se resalta que las prácticas educomunicativas son fundamentales para pensar y desarrollar una educación para y en Derechos Humanos, tanto en ambientes de enseñanza formales como no formales. 
(CC BY 4.0) | ISSN 2525-3409 | DOI: http://dx.doi.org/10.33448/rsd-v9i9.7751

Palabras clave: Sociedad red; Educomunicación; Derecho a la educación; Principio moral.

\section{Introdução}

A compreensão da educomunicação como mediadora da inserção de tecnologias no processo educativo, leva à reflexão sobre a abordagem da defesa de Direitos Humanos, na Sociedade da Comunicação e da Informação por meio de práticas educomunicativas, como forma de alcançar uma educação ética, sendo essa, a condição primordial para o desenvolvimento da cidadania e da justiça social.

A Sociedade da Comunicação e Informação evoluí de forma exponencial, o que proporciona aos indivíduos estarem conectados por meio das redes de internet em tempo real, proporcionando uma maior visibilidade para o comportamento humano. Portanto a primeira questão a ser levantada é de, como uma das bases do problema, a inserção da tecnologia na formação dos profissionais de educação, especialmente de educação em Direitos Humanos, não se dá uniformemente no Estado brasileiro. Pois ainda, os acessos às redes de internet não são uniformes.

De acordo com dados de pesquisa do IBGE (Instituto Brasileiro de Geografia e Estatística) a Pesquisa Nacional por Amostra de Domicílios Contínua - PNAD/2017demonstrou que o acesso as redes de internet não alcançam $100 \%$ de cobertura no Estado Brasileiro. E isso, por inúmeras razões, sejam porque algumas partes do território brasileiro ainda não tenham cobertura de energia elétrica, por razões de inviabilidade econômica por custos altos para a instalação e disponibilização do acesso à internet. Mesmo que o acesso à internet esteja no rol dos Direitos Fundamentais é necessário reconhecer que as mudanças são estruturais, tanto no sistema político como educacional. (IBGE, 2017).

É importante considerar os dados expostos acima, pois os processos educomunicativos refletem o momento cultural, social e tecnológico do contexto social atual. No qual a sociedade se transforma pela inserção das redes de internet aliadas ao cotidiano. Essa transformação social e cultural da sociedade canaliza-se diretamente para a educação. Além da transmissão de conhecimento entre docente e discente, é o começo para a transformação social desses atores.

Em um primeiro momento, realizou-se um levantamento histórico dos Direitos Humanos no Brasil e de maneira breve na legislação estrangeira como a Declaração Universal 
dos Direitos Humanos de 1948. A qual prevê em seu artigo $26^{1}$ o fortalecimento dos Direitos Humanos e o respeito a liberdade. Esse levantamento é fundamental para atender a uma das motivações desta pesquisa- a reflexão sobre a inserção de práticas educomunicativas voltadas para a educação em direitos humanos. Uma das motivações nesta pesquisa é a de refletir sobre como se deu a inserção dos Direitos Humanos na legislação brasileira, assim como utilizar as mídias para difundi-la de modo que faça parte da sociedade.

Para delimitar esta pesquisa, foi abordado o contexto histórico dos Direitos Humanos que está delineado pelas práticas educomunicativas voltadas para a educação em Direitos Humanos. Destacando a rápida transformação da sociedade pela inserção das redes de internet, na qual transformou as mídias em geral como uma ferramenta de transmissão de conhecimento, de reprodução e criação do saber. Contribuindo para o indivíduo atuar dentro do contexto da sociedade com efetivo exercício de cidadania.

Inúmeras são as alterações, modificações e consequências de ordem pública e particular transferidas pela Sociedade da Informação criando novas versões para o relacionamento entre os indivíduos. Frente a isso, o apanhado histórico dos Direitos Humanos, os quais foram conquistados em lenta batalha e as atuais violações sofridas frente a esse cenário tecnológico, que permite ao indivíduo conectar-se ao mundo via rede. Verifica-se a importância do uso das tecnologias para a promoção de educação em Direitos Humanos.

Para tanto, será demonstrado alguns exemplos de violações dos Direitos Humanos na Sociedade em Rede e que ferem o texto constitucional da Carta de 1988, trazendo consigo consequências desastrosas para a vida cotidiana dos indivíduos, os quais tiveram seu direito transgredido. Nesse ponto a educação para os Direitos Humanos e mais ética, tornar-se uma condição necessária, para que haja conscientização da responsabilidade ${ }^{2}$ na forma como é utilizada as redes de internet, a exemplo do compartilhamento de mensagens na sociedade online. Esse modo online faz com que a conectividade seja presente também no exercício da cidadania.

\footnotetext{
${ }^{1}$ Art. 26: Todo ser humano tem direito à educação. A educação será gratuita, pelo menos nos graus elementares e fundamentais. A educação elementar será obrigatória. A educação técnico-profissional será acessível a todos, bem como a instrução superior, está baseada no mérito.

2. A educação será orientada no sentido do pleno desenvolvimento da personalidade humana e do fortalecimento do respeito pelos direitos humanos e pelas liberdades fundamentais. A educação promoverá a compreensão, a tolerância e a amizade entre as nações e grupos raciais ou religiosos, e deve desenvolver as atividades da ONU em prol da manutenção da paz.

3. Os pais têm prioridade de direito na escolha do tipo de educação que será fornecida a seus filhos (grifo nosso), (Declaração Universal dos Direitos Humanos de 1948, Disponível em: https://nacoesunidas.org/artigo-26direito-a-educacao/).

${ }^{2}$ Quando se menciona a responsabilidade, não se está tratando apenas, da responsabilização civil de danos, mas de uma conduta responsável no agir, com bases na ética e solidariedade com os demais sujeitos da sociedade.
} 


\section{Metodologia}

Justifica-se a necessidade de práticas educomunicativas como meio informativo e de promoção de um processo educacional que pode contribuir para a promoção dos Direitos Humanos na Sociedade de Comunicação e Informação. Além disto, destaca-se que o uso das tecnologias como ferramenta de construção e difusão do conhecimento, em que envolva todos os cidadãos e lhe proporcione a participação ativa em todos os âmbitos de atuação sociais e culturais. Ressalta-se, contudo, que a referida educação vai além dos métodos escolares, sendo necessário, que os sujeitos compreendam os mecanismos de funcionamento desse mundo digital. Talvez assim se harmonizando e solidarizando-se aos demais indivíduos. Para isso, foram utilizados os métodos de abordagem dedutivo Método Dedutivo pois parte-se das fundamentações teóricas e para expressar as dificuldades enfrentadas no problema a partir das hipóteses

São formuladas hipóteses; das hipóteses deduzem-se consequências a serem testadas ou falseadas (tornar falsas as consequências deduzidas das hipóteses); enquanto o método dedutivo procura confirmar a hipótese, o hipotético-dedutivo procura evidências empíricas para derrubá-las;

E de procedimento monográfico . Como técnicas de pesquisa foram utilizadas a pesquisa bibliográfica e documental.

\section{Evolução histórica da conquista dos direitos humanos no Brasil e violações dos direitos humanos na sociedade em rede}

A história político-jurídica nacional é visivelmente marcada por um lento, porém, crescente progresso, não sem muito sacrifício de protagonistas humanos em trágicos acontecimentos sociais, e com algumas situações de retrocesso. Assim como a luta pela conquista dos direitos humanos, no mundo foi glorificada a duras penas e por meio da hecatombe de grandes heróis anônimos e, também, a incorporação dos direitos humanos nas Constituições brasileiras foi um árduo desafio aos que acreditavam nestes ideais (Gorczevcki, 2009). Para entender os Direitos Humanos é necessário que a parte histórica seja refletida, pois a dificuldade de disseminar essa ideia faz com que cada vez menos os indivíduos tenham uma visão solidarista no seu próprio desenvolvimento enquanto sujeito de direitos.

Durante diferentes períodos a humanidade passou por disputas de poder, culturais, sociais, políticas, entre outras, nos quais emergiram mudanças nas estruturas das sociedades. 
O debate acerca dos Direitos Humanos tomou força a partir do século XX. Apenas após a ocorrência de barbáries na primeira e segunda guerras mundiais é que o impacto causado a humanidade abriu espaço para a efetivação dos Direitos Humanos (Magri, 2017).

Sobre a conceituação dos Direitos Humanos, não existe um conceito fechado e aceito que corresponda satisfatoriamente a todos do que são os direitos humanos, inclusive, é um conceito objeto de disputas. De acordo com Magri (2017, p. 1) “ as concepções de Direitos Humanos não são estáticas ou fixas, mas dinâmicas que se constroem no tempo e no espaço a partir das condições existentes", portanto os Direitos Humanos são conquistas das lutas históricas e sim algo que é construído a partir dos problemas que vão surgindo.

Desta forma, a ONU em 1945 objetivando a promoção de paz, buscou a efetivação dos Direitos Humanos por meio da Carta às Nações Unidas, obrigando a promoção e efetivação a todos os Estados-membros. Em 1948, foi aprovada a Declaração Universal dos Direitos Humanos compreendidos como direitos universais, indivisíveis e inalienáveis (Magri, 2017).

Entretanto, apenas em 1822, o Brasil tornou-se independente, precisava então, estruturar-se como Estado. Assim, a Constituição Política do Império $^{3}$ do Brasil, de 1824, a qual durou mais de sessenta e cinco anos, consagrou os Direitos Humanos de primeira dimensão, inserindo-os no Título $8^{\circ}$ sob a nomenclatura de Garantia dos Direitos Civis e Políticos dos Cidadãos Brasileiros, reconhecendo por meio do art. 179 os direitos à legalidade, à irretroatividade da lei, à igualdade, à liberdade de pensamento e expressão, à inviolabilidade de domicílio, à propriedade, entre outros direitos individuais inerentes à primeira dimensão dos direitos fundamentais (Gorczevcki, 2009).

Contudo, a sociedade neste período já estava farta da monarquia, passando a objetivar uma República Federativa e presidencialista, dando-se ensejo a primeira Constituição Republicana em 1891. Na qual resultou do projeto que o governo submeteu ao Congresso Nacional dotado de poderes constituintes. Influenciado pelo ideal liberal de Ruy Barbosa e influenciado pelas teses cardeais da Constituição Norte-americana, não se cogitou para os direitos sociais do trabalhador, limitando-se a garantir o "livre exercício de qualquer profissão moral, intelectual e industrial” (conforme art. 4, Constituição Federal de 1891), (Wagner, 2010).

Dessa forma concernentes às garantias constitucionais, além de repetir o rol de direitos e garantias fundamentais já existentes na Constituição anterior, ainda foram acrescentados: gratuidade do casamento civil, ensino leigo, direito de reunião e associação, ampla defesa,

\footnotetext{
${ }^{3}$ Constituição Política do Império do Brasil foi outorgada na cidade do Rio de Janeiro, no dia 25 de março de 1824, durando mais de sessenta e cinco anos.
} 
abolição das penas das galés e do banimento judicial, abolição da pena de morte, reservadas as disposições da legislação militar em tempo de guerra, habeas corpus, propriedade de marcas de fábrica, Instituição do Júri (Wagner, 2010).

Na Constituição de 1934, com duração de cerca de três anos, menor tempo de vigência no Brasil, foram elevados os direitos e garantias trabalhistas, como normas constitucionais. Instituindo normas de proteção social do trabalhador, com isso acarretando em um grande avanço para os direitos sociais. Ao lado da declaração de direitos e garantias individuais, inscreveu um título sobre a ordem econômica e social e outro sobre a família, a educação e a cultura, com normas quase todas programáticas, sob influência da Constituição alemã de Weimar (Silva, 2001).

A Constituição de 1937 teve uma forte característica autoritária, inspirada no modelo fascista, outorgada pelo Presidente à época, Getúlio Vargas. No que se refere aos direitos e garantias fundamentais essa mostrou-se retrógrada, retirando diversos preceitos democráticos já existentes inclusive, tais como: a irretroatividade da lei e mandado de segurança foram substituídos pela pena de morte para os crimes políticos e a censura prévia da imprensa. A referida Constituição destoou de todo o percurso traçado pelas constituições anteriores (Tibiriçá; Valério, 2012).

Na realidade, no período do Estado Novo o país ficou sem Constituição, pois havia previsão para um plebiscito que o legitimaria, e, que nunca ocorreu. Conforme explica Brega Filho (2002, p. 36) “A Carta previa a realização de um plebiscito para sua legitimação e este jamais foi realizado". Previa a eleição do Congresso Nacional, mas este jamais foi eleito. Previa que após seis anos de governo seria realizado um plebiscito para uma nova legitimação da Constituição, mas isto também não ocorreu.

Assim, o país ficou sem Constituição, sem partidos políticos, sem imprensa livre, e embora o art. 122 reconhecesse direitos individuais, esses não tiveram efetividade, pois com a ditadura houve a concentração de poderes nas mãos do Presidente da República, que governava por meio de decretos-leis e de leis constitucionais (Brega Filho, 2002).

Em 1946 o país foi redemocratizado, tendo restaurado os direitos e garantias individuais por intermédio da nova Constituição, removendo-se as penas de morte e tortura. Restou garantido o habeas corpus e o mandado de segurança, o direito de reunião, bem como de criação de partidos políticos. Após a queda de Getúlio Vargas, incidiu um período de redemocratização que culminaria na promulgação da Constituição de 1946, na qual, além de restaurar os direitos e garantias individuais, reduziu-se as atribuições do Poder Executivo, restabelecendo desta forma um equilíbrio entre os poderes (Iurconvite, 2010). 
Infere-se que os avanços na prática foram pequenos, mas os avanços formais caminhavam no sentido de elevar o crescimento social do Estado brasileiro, nesta linha " $\mathrm{Na}$ prática das relações sociais, grande parte desses direitos não foram incorporados ao cotidiano da maioria dos brasileiros. Nessa época, como em outros períodos, permaneceu no Brasil uma considerável distância entre o país legal e o país real” (Fausto, 2004).

Entretanto, o país mergulhado num autoritarismo revolucionário que comandou arbitrariamente o Brasil, configurando a mais odiosa experiência de terror e violação dos direitos humanos, dando ensejo a promulgação da Constituição de 1967. A Constituição da Revolução, como ficou conhecida, aumentou os poderes da União e do Presidente da República e restringiu a autonomia individual, permitindo que houvesse a suspensão de direitos e garantias constitucionais (Gorczevcki, 2009, p. 69).

Finalmente, veio a atual Constituição Federal de 1988, com um conteúdo avançado em termos de Direitos Humanos, rompendo com uma tradição totalitária de anos de repressão e usurpação de direitos. Inaugurando um Brasil que tenta abarcar e respeitar as diferenças, assegurando um Estado democrático designado a

[...] assegurar o exercício dos direitos sociais e individuais, a liberdade, a segurança, o bem-estar, o desenvolvimento, a igualdade e a justiça como valores supremos de uma sociedade fraterna, pluralista e sem preconceitos, fundada na harmonia social e comprometida, na ordem interna e internacional, com a solução pacífica das controvérsias (Gorczevcki, 2009, p. 71).

Para compreender melhor a violação dos direitos humanos na Sociedade da Informação, faz-se necessário um apanhado hermenêutico breve da evolução da tecnologia até a sociedade contemporânea. Com o surgimento dos danos na sociedade da informação, são alteradas as formas de compreensão de suas extensões, tais como o reflexo na sociedade.

Desta maneira, vislumbrando a coletividade, é necessário a inserção de um pensamento mais solidarista em relação a esfera privada, e essa ideia vem crescendo no Direito, sendo alavancadas por problemas mais sociais do que individuais. Para tanto é necessário que seja disseminada uma educação para os Direitos Humanos por intermédio das tecnologias, visto que esta inserção poderá propagar e alcançar um número bem expressivo de ouvintes devido ao alcance das redes de internet.

Percebe-se em uma visão mais alargada do Direito, partindo do viés da coletividade, que essa esbarra na própria sociedade da informação. Apesar dos efeitos modificativos culturalmente, de costumes e cultural a criação das comunidades sociais proporcionaram um 
maior isolamento pessoal. Verifica-se que a facilidade da comunicação de muitos com muitos sem barreiras físicas conforme preceitua Castells (1999), na realidade causa um afastamento instantâneo das pessoas.

Essa transição social teve início pelas redes sociais da internet, com poucos, aos quais se juntaram centenas de indivíduos, depois formaram-se uma rede de milhares de criando sociedades virtuais. Há muitos questionamentos acerca do que é real nas comunidades virtuais, Castells afirma que é temerária uma única resposta por se tratarem de comunidades que refletem o plano virtual a partir plano físico. E que poderiam enquadrar-se ou não como comunidades reais. Entretanto, essa comunidade virtual vincula-se por laços fracos, já que há a possibilidade de inserção de perfis falsos nas redes, bem como perfis que o indivíduo deseje expor criar uma imagem dele mesmo sem que essa imagem tenha indícios de realidade (Castells, 1999).

Exercendo assim a liberdade de expressão e pensamento, justamente como um dos pilares do Estado democrático de Direito. Cabe lembrar que a liberdade de expressão é um dos direitos individuais mais importantes de uma sociedade, sem o qual, não poderá haver a democracia. Corroborando como verdadeiras tais afirmações, se observar regimes com tendências totalitárias, a liberdade de expressão é sempre um dos primeiros direitos a serem restringidos, sob o suposto argumento de que o sistema deve ser preservado (Uebel, 2011).

Contudo é questionável o fato da não compreensão por parte da sociedade, de que a Sociedade da Informação não é apenas virtual, já que estabelece reflexos em todas as áreas do conhecimento, gerando repercussões nas relações humanas, inclusive com os reflexos jurídicos (Lisboa, 2006). O uso da liberdade de expressão como escudo da violação de direitos personalíssimos já não se aplica mais a sociedade contemporânea.

A seguir alguns exemplos de violações dos Direitos Fundamentais como pode-se verificar tais violações por meio das notícias que circundam as redes, como exemplo, a atriz de nome artístico, Cris Vianna , após compartilhar foto em sua rede social (facebook), foi alvo de comentários preconceituosos e de cunho racista, tais como: "Já usou esse cabelo para lavar a casa hoje, Africana?". "Parece o Bombril que minha mãe usa na pia", "sua primata africana", "Cadê o Ibama para tirar esse porco espinho do Facebook", "macaca" (Ego, 2015).

Outro exemplo, neste seguimento, é o caso de Diogo Medeiros, em que, após ter sido aprovado no vestibular para o curso de medicina, foi atacado com comentários racistas após publicar mensagem de incentivo 'aos estudos' em um grupo de medicina. Alguns comentários realizados foram: "Ué, não sabia que negro podia ser médico, quem se arriscaria em uma consulta?", "Só porque o cara é feio e da cor de fita isolante ele não pode ser feliz?", "Se não 
tivesse cota duvido que conseguiria", "Temos que acabar com o preconceito entre negros e humanos (sic)" (Pragmatismo Político, 2015).

Entre tantos exemplos, que circulam diariamente nas redes de internet, percebe-se que, em grande medida, o público alvo que é constantemente agredido, apesar da proibição Constitucional, possuem como motivação questões que envolve a orientação sexual e a identidade de gênero, tais como: como a comunidade de lésbicas, gays, bissexuais, transgêneros e intersexuais (LGBTI)). Não ficam de fora das redes sociais, as violações contra crianças e adolescentes, vítimas de cyberbullying. Inúmeros são exemplos diários de violações aos Direitos Humanos na sociedade em rede, essa conclusão reforça a necessidade de práticas educomunicativas voltadas para a educação em Direitos Humanos.

Há várias ferramentas educacionais que além de informativas são construídas diariamente com a ajuda dos usuários das redes de internet, que muitas vezes não são divulgadas para que possa se tornar um assunto a ser refletido com mais frequência. No Brasil, foi criado o Pacto Nacional de Enfrentamento às Violações de Direitos Humanos na internet (Humaniza Redes), por iniciativa do Governo Federal em ocupar esse espaço usado pelos brasileiros, para garantir mais segurança na rede quanto às violações de Direitos Humanos que acontecem online, através de denúncia, prevenção e segurança, visando garantir aos usuários, principalmente, as crianças e adolescentes, uma pretensa internet livre de violações de Direitos Humanos (Humaniza Redes, 2013).

\section{Práticas educomunicativas voltadas à promoção dos Direitos Humanos}

Conforme exposto no capítulo anterior a trajetória difícil de se alcançar e atingir o reconhecimento dos Direitos Humanos, e como a Sociedade da informação está inserida no cotidiano dos indivíduos, percebe-se que há a necessidade do uso das tecnologias como forma de propagação de uma educação voltada para os Direitos Humanos.

A Sociedade da Informação vem gerando "vácuos" em diversos ramos, a ponto de a educação principiológica e ética ser condição necessária para o exercício digno de cidadania. Assim proporcionará uma maior conscientização dos indivíduos, a fim de minimizar as atuais violações decorrentes desta conectividade e desterritorialidade dos indivíduos proporcionada pelo meio virtual.

Apesar de um desafio global e bastante complexo para a educação, a propagação descontrolada do saber, com um crescimento desmedido, e por consequência " $\mathrm{O}$ crescimento ininterrupto dos conhecimentos constrói uma gigantesca torre de Babel, que murmura 
linguagens discordantes" (Morin, 2003, p. 16). Quando se soma isso a sociedade da informação, percebe-se a potencialização do desequilíbrio dos saberes, da comunicação, tornando-se se um desafio, o agir, de forma ética e solidária, harmonizando-nos aos incrementos impostos pela Sociedade do Conhecimento.

Apesar dos esforços auferidos para acompanhar os avanços tecnológicos, é necessário muito mais, como por exemplo, readequações instrucionais e educacionais, os quais sejam iminentes em assegurar os direitos constitucionais previstos na Constituição Federal de 1988. Aumentar o alcance aos documentos e fontes que asseguram os Direitos Humanos a fim de atingir um maior número de indivíduos. Nesta linha o espaço de comunicação e educação não podem ser promovidos apenas em espaços formais, portanto, ocorre uma lacuna entre as readequações institucionais e a inserção da sociedade do conhecimento, transparecendo em algumas vezes que não há alinhamento entre elas.

Para tanto, uma das hipóteses a ser verificada é o aumento destas relações de comunicação em espaços educativos. Buscando conceituar a educomunicação, Soares argumenta que "[...] às relações de comunicação em espaços educativos, buscando a implementação de uma gestão democrática dos recursos da informação com a participação de professores, estudantes e membros da comunidade educativa" $(1999$, p.......). Destarte essas relações propiciam um maior acesso ao saber aumentando as possibilidades de acesso ao conhecimento, sendo justamente uma hipótese positiva como solução ao aliar as redes de internet, a educação e a promoção de Direitos Humanos.

Para entender melhor, Geneviève Jacquinot sustenta que o educomunicador é um profissional do século XXI, que alia diferentes alternativas as suas práticas pedagógicas. Os desafios atuais é justamente contrapor a educação tradicional promovendo um pensamento crítico desse educando (Jacquinot, 1998). Conforme o levantamento histórico, apresentado acerca dos Direitos Humanos, mostra que sendo ou não abarcados pelas constituições que se sucederam, e demonstram como o indivíduo dotado de criticidade deve refletir para reproduzir o conhecimento utilizando as ferramentas disponíveis. Com tais alternativas o educador pode promover a capacidade de análise dos referenciais que esses educandos utilizam na sociedade em rede. Alinhando esse educando a uma conduta preventiva para as violações dos Direitos Humanos, nas redes de internet. A busca pela educação crítica e preventiva pode apresentar resultados satisfatórios a longo prazo.

Tanto a escola quanto a sociedade em rede são condutores da formação dos sujeitos individualmente e na coletividade. A escola valoriza a objetividade das disciplinas ensinadas, enquanto que os meios midiáticos valorizam a subjetividade bem como pela atualidade, pela 
promoção da surpresa dos acontecimentos, buscando a formação de um público consumidor. A escola trabalha com princípios mais duradouros sem imediatidade, procura formar cidadãos (Jacquinot, 1998).

Essa oposição das duas linhas transmissoras do saber, faz com que a gestão na escola, preocupa-se mais com a seleção dos conteúdos que serão trabalhados e transmitidos pelos educadores. O conhecimento na escola é trabalhado a longo prazo com avaliações dos educandos de forma sistemática. Entretanto nos meios digitais esse saber descontinuado, as influências externas bem como a compilação de saberes sem qualquer seleção não trazem ao educando um controle de aquisição desses saberes (Jacquinot, 1998).

Quando se constata esse massivo meio de transmissão de conhecimento desordenado verifica-se que o problema não está na quantidade de informação e sim como são interpretadas. A sociedade em rede fornece esse meio com toda a informação que as redes de internet posam dispor, portanto como lidar com essas informações é fundamental para os educandos. Por mais estudos divulgados e informações disponíveis nas redes de internet sobre as práticas de violações de Direitos Humanos, de racismo, xenofobia, cibercrimes, elas são apenas informativas se os educandos não se utilizarem de tais informações para prevenção desses atos.

O desafio da sociedade contemporânea é garantir o cumprimento destes diretos. Conforme visto inicialmente tanto no mundo quanto no Brasil a ratificação e a fixação desses direitos foi lento e complexo. Atualmente a forma mais eficiente de promoção dos direitos humanos se dá pela educação. A educação não se objetiva na construção de um pensamento crítico capaz de alterar o comportamento humano fazendo com que sejam possíveis a formação de cidadãos em que promovam uma relação de humanidade entre os sujeitos.

Neste contexto dos cidadãos conectados ao mundo, o aspecto cultural e instrucional deverá ser implementado, orientado, amadurecido, alimentado de forma intelectualizada e direcionada, não apenas na informática, mas principalmente na busca da informação, estimulando e orientando o educando a buscar o conhecimento, viabilizando as relações com mais ética e humanidades.

Claro que não se pode olvidar do contexto histórico em que a educação formal é precária no Brasil em muitas instituições, portanto cabe ao Poder Público implantar formas de incentivos a fim de buscar instrumentos e conhecimentos adaptando-se a sociedade contemporânea. A educação necessária não é restrita ao âmbito escolar, pois estas informações são superadas com a velocidade da sociedade do conhecimento. É necessária 
uma educação voltada ao desenvolvimento da educação ética nas relações humanas (Castells, 1999).

De acordo com Cortina (1995) a existência das pessoas é, pois, a razão de que haja obrigações morais, porque, como são valiosas em si mesmas, não há equivalente para cada uma delas, assim como não há possibilidade de fixar-lhes um preço. E, acrescenta-se, como a melhor via para superar ou contornar a instrumentalização da educação popular e do trabalho da cultura é a sua instrumentação intelectual e prática, ensinando os indivíduos a emanciparem seu projeto fundador e central (Petrovic, 2006).

A educação é algo que tem que se dar, que deve acontecer, com a qual estamos obrigados e dela necessitamos para sermos humanos e é neste sentido preciso de obrigação como necessidade que devemos melhorar (É a educação um direito humano? Em busca de razões suficientes para se justificar o direito de formar-se como humano (Andrade, 2013).

De fato, o estudo dos direitos humanos conduz, necessariamente, à análise de sua relação com o próprio homem, seu destinatário. Dessa maneira, no plano histórico, busca-se a justificação dos valores naquilo que representam ao homem, que lhe possibilitem o desenvolvimento da personalidade, da convivência pacífica e da solidariedade social. No tocante à definição de direitos humanos, constata-se que isso vem sendo feito de modo vago e insatisfatório, ainda mais quando se busca um fundamento absoluto, único.

Salienta-se que a maioria das habilitações de uma pessoa, obtidas no trabalho ou na escola, mesmo no nível superior, atualmente, acabam por ser rapidamente superadas. Eis que a renovação veloz e constante do conhecimento é um dos principais elementos que caracterizam a chamada Era da Informação (Castells, 1999). Para tanto, faz-se útil e necessário o domínio de metodologias de análise em comunicação nos projetos voltados para a educação em direitos humanos. Além do exercício da prática comunicativa a partir do protagonismo dos sujeitos sociais.

O termo tem sido adotado como política pública, em diferentes níveis de governo, nas áreas da educação e do meio ambiente, a partir de uma pesquisa desenvolvida pelo Núcleo de Comunicação e Educação da USP, entre 1997 e 1999 (Soares, 1999). A educação midiática como uma

prática voltada à análise do impacto dos meios de comunicação na sociedade e à promoção do uso pedagógico dos recursos das tecnologias da comunicação e informação no cotidiano do ensino - esteve presente no Brasil através de ações esporádicas e localizadas, vinculadas à boa vontade de lideranças, tanto no âmbito da educação não formal quanto no espaço da formalidade escolar, chegando a contar, em 
alguns casos, com o apoio da estrutura de secretarias de educação (Soares, 2018 p. 11).

Neste sentido, a educação, compreendida como um compromisso com a pessoa, com o ser humano, não só pode como deve desempenhar um papel fundamental na construção e no desenvolvimento de uma consciência cidadã, preocupada com a defesa dos Direitos Humanos e com a afirmação da Cidadania, pois como afirma Gadotti, na educação (do homem) a raiz é o próprio homem. O essencial da reflexão sobre a educação é a condição humana, o homem, a antropologia (Gadotti, 1981).

Assim conclui-se que a inserção de práticas educomunicativas impedem o retrocesso ao conhecimento, o saber acerca dos Direitos Humanos, em detrimento da evolução tecnológica e, sim, utilizar esta evolução de conexão e comunicação como forma de propagar esse conhecimento. Assim por meio de práticas educomunicativas proporcionar a disponibilização de uma educação voltada aos Direitos Humanos e as humanidades. Demonstrando a necessidade de práticas éticas, morais e solidaristas de uns em relação a outros, enquanto sujeitos de direito.

\section{Considerações Finais}

Percebeu-se no início da pesquisa a evolução histórica da Constituição brasileira, compreendendo direitos, dentre os quais foram citadas a liberdade de expressão, fruto do Estado Democrático de Direito, direitos sociais, entre outros. Ainda um breve apanhado da inserção dos Direitos Humanos no contexto brasileiro. Entretanto, estabelecer regras éticas e morais para que a liberdade de expressão de alguns não viole garantias fundamentais de outros, por meio da violação dos Direitos Humanos, é necessária uma promoção para disseminar uma educação voltada aos Direitos Humanos, tanto em ambientes formais como não formais buscando assim a efetivação desses.

Desta maneira infere-se a necessidade de equalizar a educação, por meio de um ensino mais humanístico, utilizando-se de práticas da educação digital, para proporcionar um maior alcance da informação. Utilizando a velocidade das redes de internet como canalizadora para a disseminação de conhecimento. Contudo não se trata de um saber desordenado, mas sim um conhecimento objetivo a duradouro. Para reforçar que a transmissão do saber aos educandos, seja voltada às práticas voltadas para os Direitos Humanos.

Verificou-se que as práticas educomunicativas podem ser uma base propulsora para a disseminação de conhecimento acerca dos Direitos Humanos. Apesar de perceber as lacunas 
existentes entre o que está definido em letra de lei e o reflexo da sociedade no qual, não reflete o que prescreve a Constituição Federal. Porém estas lacunas podem ser tratadas por meio da educação, assim poderão ser fortalecidos e reconhecidos os Direitos Humanos para indivíduos da sociedade contemporânea que sequer os conhecem.

Considerando que apesar de inúmeros benefícios que a internet alavancou, também há readequações iminentes a serem observadas para que o compartilhamento de informações não seja utilizado, como palco de violação dos direitos humanos. Para tanto, indica-se a educação ética de nível primário, fundamental e médio para orientar o cidadão neste contexto em rede, por meio dessas interações de práticas pedagógicas entre a escola, a sociedade e as possibilidades ofertadas pelas redes de internet.

Importante frisar que o advento das redes de Internet, tornaram-se instrumentos para que os indivíduos participem de forma ativa no contexto da Sociedade Informacional. Exatamente por esse exposto, a importância do saber aliado a novos meios de conhecimento como prevenção a violações na sociedade da informação. Contudo, para se falar em cidadania, é preciso ter em mente uma educação ética e solidária. As práticas educomunicativas podem ser utilizadas como elo de ligação entre a inovação tecnológica e a sala de aula.

\section{Referências}

Andrade, M. (2013). Educação. 36(1), 21-27, jan./abr. Porto Alegre, impresso.

Assissio Magri, C. A (2020). Educação em, com e para os Direitos Humanos a partir de Paulo Freire. Recuperado de https://docplayer.com.br/18637522-A-educacao-em-com-epara-os-direitos-humanos-a-partir-de-paulo-freire.html.

Brasil. (1988). Constituição Federal. Recuperado de http://www.planalto.gov.br/ccivil_ 03/constituicao/constituicao.htm.

Brega Filho, V. (2002). Direitos Fundamentais na Constituição de 1988: Conteúdo Jurídico das Expressões. São Paulo: Editora Juarez de Oliveira, 36. 
Castells, M. (1999). A Sociedade em Rede (A Era da Informação: economia, sociedade e cultura, v. 1). Tradução de Roneide Venâncio Majer, atualização para (6a ed.), Jussara Simões. São Paulo: Paz e Terra.

Declaração Universal dos Direitos Humanos. Assembleia Geral das Nações Unidas em Paris. 10 dez. 1948. Recuperado de https://nacoesunidas.org/artigo-26-direito-a-educacao/.

Ego, 'Covardemente atacada', diz Cris Vianna após sofrer racismo na web. Recuperado de http://ego.globo.com/famosos/noticia/2015/11/cris-vianna-e-vitima-de-racismo-na-internetassim-como-tais-araujo.html.

Fausto, B. (2004). História do Brasil. (12a ed.), São Paulo: Editora da Universidade de São Paulo, 399.

Gadotti, M. (1981). A educação contra a educação. Rio de Janeiro: Editora Paz e Terra.

Gorczevcki, C. (2009). Direitos Humanos, Educação e Cidadania: Conhecer, Educar e Praticar. Santa Cruz do Sul: Editora Edunisc, 180/181.

Humanizaredes, (2020). Recuperado de http://www.humanizaredes.gov.br/o-que-e/.

Instituto brasileiro de geografia e estatística. (2017), Recuperado de https://www.ibge.gov .br/busca.html?searchword=acesso\%20a\%20internet\&searchphrase=all.

Iurconvite, A. S. (2010). A evolução histórica dos direitos sociais: da Constituição do Império à Constituição Cidadã. In: Âmbito Jurídico, Rio Grande, XIII, n. 74, mar. Recuperado de http://www.ambito-juridico.com.br/site/index.php?n_link=revista_artigos_leitura\&art igo_id=7417.

Jacquinot, G. (1998). O que é um educomunicador. São Paulo: USP.

Lisboa, R. S. Direito na Sociedade da Informação. Recuperado de https://www. lexml.gov.br/urn/urn:lex:br:rede.virtual.bibliotecas:artigo.revista:2006;1000775406. 
Petrovic, N. B. (2006). A educação popular às voltas com a Sociedade da Informação: potencialidades, riscos e particularidades, Liinc em Revista, v.2, n.1, março 2006, p.22-39. Recuperado de http://www.ibict.br/liinc.

Pragmatismo político. (2015). Recuperado de http://www.pragmatismopolitico. com.br/2015/10/aprovado-em-vestibular-de-medicina-jovem-negro-sofre-racismo-nainternet.html.

Silva, J. A. (2001). Curso de direito constitucional positivo. Editora Malheiros. (20a ed.). São Paulo.

Soares, I. O. (1999). Comunicação/educação: a emergência de um novo campo e o perfil de seus profissionais. Contato, Revista Brasileira de Comunicação, Arte e Educação, Brasília, DF, 1(2), 19-74.

Tibiriçá, S., \& Valério, A. F. Brasil cria comissão da verdade, oxímora revista internacional de ética y política núm. 1. otoño 2012. issn 2014-7708. 197-212.

Uebel, P. (2011). A Mídia Tradicional, as Novas Mídias e a Liberdade de Expressão. In: CHARNESKI, Heron. (coord.). A Liberdade na Era Digital. Porto Alegre: Instituto de Estudos Empresariais, 76.

Wagner, D. (2010). Direitos Humanos e Garantias Fundamentais nas Constituições Brasileiras. Recuperado de http://www.grancursos.com.br/downloads/2010/artigos/ direitoshumanosegarantias.pdf.

\section{Porcentagem de contribuição de cada autor no manuscrito}

Tatiane de Fátima da Silva Pessôa - 40\%

Taís Steffenello Ghisleni - 30\%

Marcos Alexandre Alves - 30\% 